of an analyte specific clean-up is useful in minimizing this problem. Identification of the species producing the effect and application of specific clean-up steps can eliminate problems.

Low results can result from incomplete analyte extraction, loss or degradation of the analyte during sample clean-up, or matrix effects. These problems can be eliminated by a careful evaluation of each of the steps employed in the sample preparation.

1) Extraction efficiencies can be improved by dissolving the sample matrix whenever possible and determining the optimum solvent for analyte extraction. When dissolution of the matrix is not practical, an exhaustive extraction procedure with an optimum solvent should be used.

2) Loss or degradation of the analyte can be controlled by determining the recoveries of all analytes through each clean-up step. An understanding of the chemical and physical properties of the analyte will not only improve recoveries, but also can allow optimization of each clean-up step.

3) Matrix effects leading to low results generally are caused by exceeding the capacity of the clean-up procedure for either analytes, related compounds, or coextractive species. This "overloading" can change the chromatographic retention of the analyte. In general, these effects can be minimized by decreasing the sample size or using a highcapacity pretreatment step to remove the coextractives.

Application of these precautions can result in a method which does not generate false positive or false negative results. A recent collaborative study to determine fortified levels of CDDs and CDFs in human adipose tissue at $5-50 \mathrm{pg} / \mathrm{g}$ has been completed by eight laboratories highly experienced in the determination of CDDs and CDFs [Albro et al., Anal. Chem. 57, 2717 (1985)]. By implementing the practices described above, laboratory 2 avoided generating either unaccountably high or low results (table 1).

The apparent drawback of the laboratory 2 method is the relatively long analysis time per sample. However, when the standard deviation of the recoveries for each laboratory is calculated and used in the equation to determine the relative time to analyze $N$ samples (measurements necessary to yield data of defined statistical reliability), method 2 can actually generate data with a specified precision in the shortest time.
Table 1. Interpretation of recovery data from CDD/CDF collaborative study

\begin{tabular}{|c|c|c|c|c|c|c|c|c|}
\hline \multirow{2}{*}{\multicolumn{2}{|c|}{$\begin{array}{l}\text { Avg. analy- } \\
\text { sis time } \\
\text { days/sample } 0.9\end{array}$}} & \multirow[t]{2}{*}{ Lab 2} & \multirow[t]{2}{*}{ Lab 3} & \multirow[t]{2}{*}{ Lab 4} & \multirow[t]{2}{*}{ Lab 5} & \multirow[t]{2}{*}{ Lab $6 \mathrm{I}$} & \multirow[t]{2}{*}{$\mathrm{Lab} 7 \mathrm{~L}$} & \multirow[t]{2}{*}{$\mathrm{ab} 8$} \\
\hline & & & & & & & & \\
\hline $\begin{array}{l}\text { Number of } \\
\text { values unac- } \\
\text { countably } \\
\text { high }\end{array}$ & 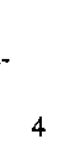 & 0 & 2 & 6 & 2 & 3 & 16 & 3 \\
\hline $\begin{array}{l}\text { Number of } \\
\text { values unac- } \\
\text { countably } \\
\text { low }\end{array}$ & 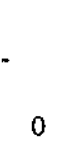 & 0 & 0 & 1 & 10 & 8 & 7 & 0 \\
\hline $\begin{array}{l}\text { Avg. re- } \\
\text { covery }\end{array}$ & $115 \%$ & $97.7 \%$ & $114 \%$ & $147 \%$ & $97.0 \%$ & $650.3 \%$ & $135 \%$ & $6151 \%$ \\
\hline $\begin{array}{r}\sigma(\mathrm{S} . \mathrm{D} . \\
\text { rec. })\end{array}$ & $51 \%$ & $19 \%$ & $48 \%$ & $94 \%$ & $143 \%$ & $39 \%$ & $123 \%$ & $64 \%$ \\
\hline$n$ & 26 & 23 & 23 & 26 & 23 & 26 & 23 & 25 \\
\hline $\begin{array}{l}\text { Rel. time } \\
\text { to } N\end{array}$ & 2.5 & 1 & 1.5 & 9.2 & 22 & 2.4 & - & 11 \\
\hline
\end{tabular}

\section{Pharmaceutical Trace Analysis}

\section{Scott Aldrich, Steven J. Borchert, Amy Abe', and James E. Freeman}

\author{
The Upjohn Company \\ Kalamazoo, MI 49001
}

Trace analysis can have various meanings, depending on the context of the problem at hand. This paper focuses on one aspect of trace analysis relevant to quality control in the pharmaceutical industry. Trace levels of contaminants in pharmaceutical materials and products can present significant analytical challenges in many ways. For example, organic impurities in drugs and drug products are typically controlled to levels from $0.01-1.0 \%$. Detecting and quantitating species at these levels represents a complex problem in

\footnotetext{
'The Sherwin-Williams Company, Chicago, IL.
} 
mixture analysis. The development of such methods frequently. requires the analysis of overlapped chromatographic peaks and chemically labile species. For compounds of acute toxicological concern, part-per-billion (ppb) levels must sometimes be monitored. Apart from toxicology issues, some chemical contaminants present at a few ppm can produce undersirable color or odor in a product.

Although the above examples represent everyday problems in pharmaceutical trace analysis, the focus of this paper is in another area: the detection, identification, and control of trace levels of insoluble material in drug solutions. Insoluble materials can occur as individual particles visible to the eye, visually perceptible haze, or subvisible particles. Some medical evidence of the consequences of particulate matter entering the bloodstream does exist [1-3]. Furthermore, various compendial regulations limit the numbers and sizes of particles allowed in parenteral drug products [4-6]. For example, no particles visible to the eye may be present. Recent trends within the pharmaceutical regulatory community indicate increasingly restrictive requirements pertaining to particulate matter.

The particle size range of interest for pharmaceuticals is $5-100 \mu \mathrm{m}$. The lower limit is determined by the size of capillary blood vessels, and the upper limit is the threshold of visible detection. That this type of contamination is a trace analytical problem can be appreciated from the data in table 1. The concentrations of particles fall in the ppm range, and typically as little as a few nanograms of material must be detected and analyzed.

Table 1. Mass and concentration of $1 \mathrm{~g} / \mathrm{cm}^{3}$ spherical particles at various regulatory limits

\begin{tabular}{ccc}
\hline \hline Limit & $\begin{array}{c}\text { Particle mass per } \\
\text { container } \\
(\mu \mathrm{m})\end{array}$ & $\begin{array}{c}\text { Particle } \\
\text { concentration } \\
(\mathrm{ppb})\end{array}$ \\
\hline $\begin{array}{c}\text { One 100- } \mu \text { m particle per } \\
\text { 10-mL container }\end{array}$ & 0.52 & 52. \\
1000 2- $\mu \mathrm{m}$ particles per mL & 0.0042 & 4.2 \\
$1005-\mu \mathrm{m}$ particles per $\mathrm{mL}$ & 0.0065 & 6.5 \\
50 10- $\mu \mathrm{m}$ particles per $\mathrm{mL}$ & 0.026 & 26. \\
$525-\mu \mathrm{m}$ particles per $\mathrm{mL}$ & 0.041 & 41. \\
\hline
\end{tabular}

Because particulate matter must be controlled on a routine basis, the best approach to dealing with such problems is in the formulation and manufacturing design stages. We have followed this strategy: (1) detection and problem definition, (2) isolation and sample preparation, (3) identification, and (4) elimination of the mechanism of particle formation [7]. The following discussion includes brief descriptions of each of these points and examples of actual problems we have encountered.

The characteristics of human and instrumental particle-detection technology have been thoroughly described in the literature ([7], and references therein). Two alternatives exist for detecting "visible particles," i.e., particles $>100 \mu \mathrm{m}$. Human visual inspection, while sensitive and selective as to its ability to classify particle types, suffers from inspector fatigue and poor reproducibility. This process has been shown to be probabilistic, not deterministic: it cannot detect visible particles with $100 \%$ certainty. Machine visual inspection is more reproducible and possesses a lower particlesize detection limit. Subvisible particles must not only be detected, but also sized and counted. A number of instrumental approaches to this problem have been developed, but the method based on detecting and sizing particles by their ability to block a light beam has been almost universally adopted by the pharmaceutical industry.

Proper definition of the problem as, for instance, individual large particles, haze, etc. is important for the next steps, which involve isolation of the particles and preparing them for analysis. Commonly, only a small number of product containers with only a few particles are available for analysis. The most common isolation techniques are filtration and single-particle isolation by micropipette. The surface on which particles are isolated can determine what subsequent analytical techniques can be applied. We have found the use of gold-coated membrane filters to be particularly useful when surfacesensitive spectroscopic techniques are to be used.

Microscopy is invariably the first technique applied to particle analysis: microscopy is sensitive, with a detection limit of one picogram, and it is ideally suited to assessing the heterogeneity of the isolated particles. Light microscopy techniques can determine refractive index, crystal form, solubility, thermal properties, and some chemical properties. Elemental analysis (scanning electron microscopy/ x-ray fluorescence, ESCA), molecular spectroscopy (infrared, Raman, mass spectrometry), and other techniques (light scattering, $x$-ray diffraction, chromatography) must frequently be used to completely identify particulate matter. Importantly, SEM/XRF, Raman, and infrared spectroscopy can each be used to analyze nondestructively single particles. 
Identification includes not only chemical identity, but also the source of the particles. Particles can arise from the manufacturing environment, packaging materials, or the drug solution itself. The examples described below illustrate two such sources. Once the mechanism of particle formation is understood, steps to eliminate it from the product design can be taken.

In the first example, large visible particles were detected in a diluent solution used for reconstituting lyophilized drug powders. The solution contained water, methyl and propyl paraben, and sodium pantothenate. Microscopy revealed a heterogeneous matrix, one component of which was identified by infrared spectroscopy as silicone oil. SEM/XRF analysis revealed the presence of $\mathrm{Cu}$ and $S$; the remainder of the particles was organic in nature. Using $x$-ray fluorescence and atomic absorption spectroscopy, $\mathrm{Cu}$ was quantitated in solution at about $1 \mathrm{ppm}$ and traced to the lot of sodium pantothenate used for these preparations. Product manufactured from other lots of sodium pantothenate containing lower levels of $\mathrm{Cu}$ did not produce a significant amount of precipitate.

Copper alone could not account for the formation of the precipitate, and the presence of silicone oil implicated the lubricated rubber stoppers. A series of experiments demonstrated that both the presence of $\mathrm{Cu}$ and contact with the rubber stoppers used in the product were necessary to form particles. Subsequent mass spectral analysis of the particles confirmed the presence of a common vulcanizing agent, 2-mercaptobenzothiazole (MBT). MBT is known to be extracted from rubber by contact with aqueous solutions, and its reaction with $\mathrm{Cu}$ yields a highly insoluble complex [8-10]:

$$
\mathrm{Cu}+2 \mathrm{MBT}=\mathrm{Cu}(\mathrm{MBT})_{2}, \quad K_{\mathrm{sp}}=10^{-21} .
$$

Experiments confirming the $\mathrm{Cu}$ concentration dependence of particle formation, as well as identification of the individual components, were important to discovering this mechanism. An obvious solution to this problem is the use of stoppers which do not contain MBT.

In the second example, particles were observed as a fine "smoke" in a new product under development. Interestingly, the smoky character of the particles prevented their detection by machine inspection; only careful human inspection revealed their presence. Microscopically, these particles were amorphous flakes $10-30 \mu \mathrm{m}$ in size. SEM/XRF analysis did not detect elements of atomic number
$>9$. ESCA detected significant amounts of only C and $\mathrm{O}$, and high-resolution measurements suggested the presence of an ester functional group. Infrared analysis detected carbonyl and $\mathrm{C}-\mathrm{O}-\mathrm{C}$ stretching frequencies characteristic of aromatic esters, and Raman spectroscopy confirmed the presence of aromatic functionality with a band at $1000 \mathrm{~cm}^{-1}$. Mass spectrometry revealed several series of repeating mass fragments and, hence, the polymeric nature of the particles. A detailed analysis of the infrared and mass spectra (figs. 1 and 2), followed by analysis of specially synthesized authentic material, confirmed the identity of the particles as poly(diethyleneglycol)isophthalate. This material was subsequently traced to filtration equipment used during synthesis of the drug.

These examples illustrate the wide range of techniques which can be used to identify particulate matter. Detection and resolution of such problems contributes significantly to the design and manufacture of high-quality pharmaceutical products.

\section{Acknowledgments}

The authors would like to acknowledge the contributions of Robert S. Chao, Frank W. Crow, Wayne K. Duholke, Lloyd E. Fox, Ronald W. Maxwell, and Robert D. White.

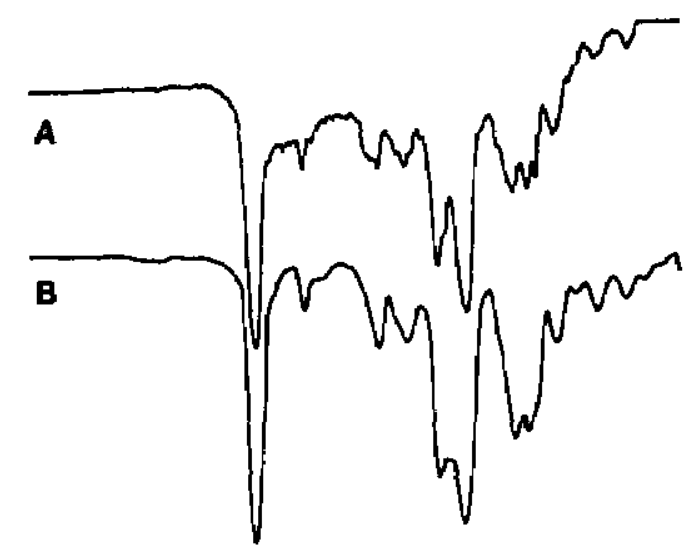

$\begin{array}{lllll}2250 & 1550 \quad \begin{array}{l}1650 \\ \text { WAVENUMBERS }\end{array} & & 1350 & 750\end{array}$

Figure 1. Infrared spectra of (A) particles and (B) synthetic poly(diethyleneglycol)isophthslate. 


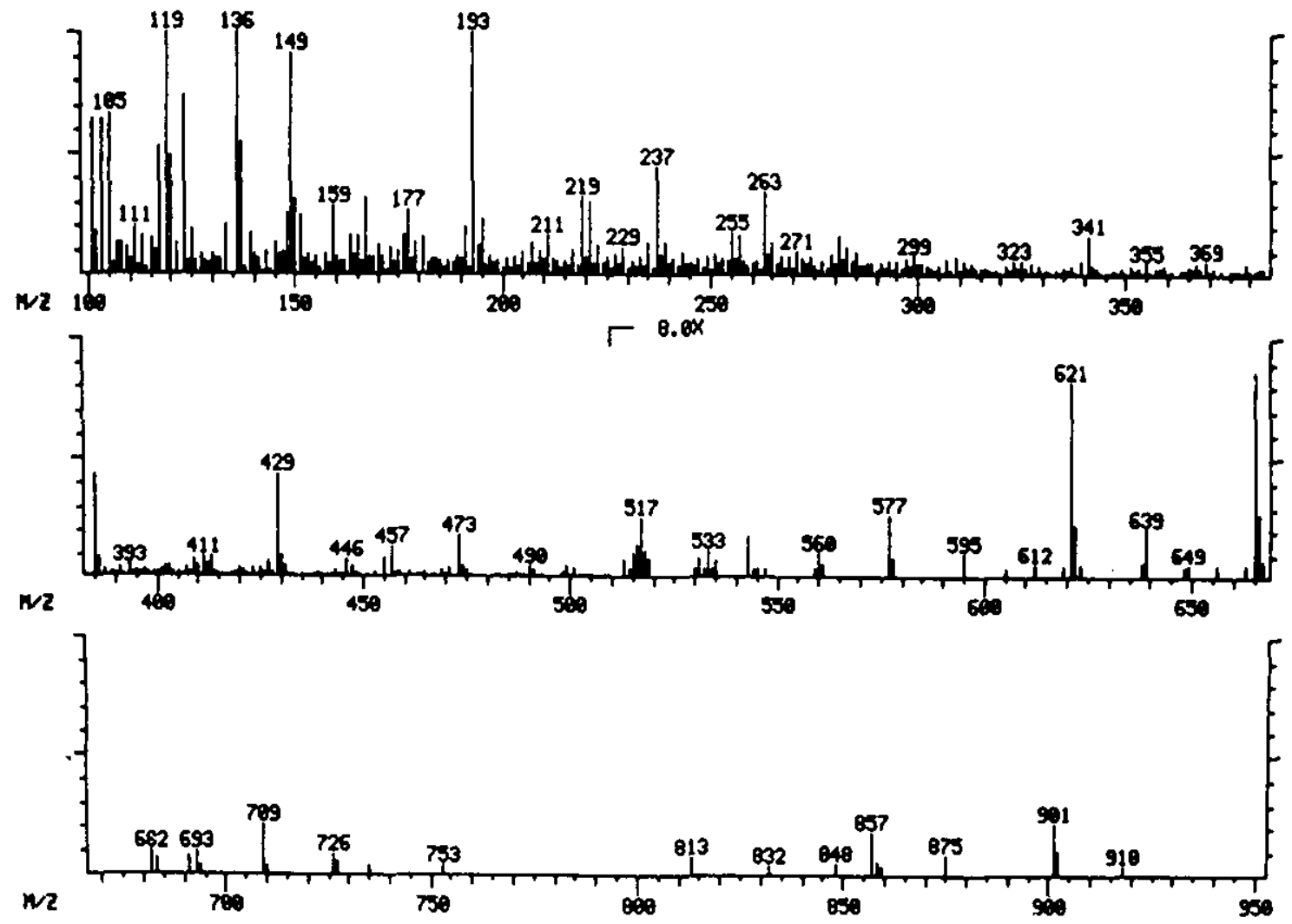

Figure 2. Desorption chemical ionization mass spectrum of particles.

\section{References}

[1] Turco, S., and Davis, N. M., Hosp. Pharm. 8, 137 (1973).

[2] Thomas, W. H., and Lee, Y. K., N. Z. Med. J. 80, 170 (1974).

[3] Akers, M. J., Parenteral Quality Control: Sterility, Pyrogen, Particulate, and Package Integrity Testing, Marcel Dekker, Inc., New York (1985) p. 143.

[4] The United Stated Pharmacopoeia, Twenty-First Revision, Mack Publishing Company, Easton, PA (1984).

[5] British Pharmacopoeia 1980, Volume II, University Press, Cambridge (1980).

[6] The Pharmacopoeia of Japan, Part I, Tenth Edition, Yakuji Nippo, Ltd., Tokyo (1982).

[7] Borchert, S. J., Abe, A., Aldrich, D. S., Fox, L. E., Freeman, J. E., and White, R. D., J. Parenteral Sci. Technol. 40, 212 (1986).

[8] Boyett, J. B., and Avis, K. E., Bull. Parenteral Drug Assoc. 29, 1 (1975).

[9] Prajapati, S. N., et al., J. Inst. Chem. Calcutta 47, 99 (1975).

[10] Rusina, O. N., Mater. Nauch-Tekh. Kanf Sev-Kavkaz Gornomet. Inst. 69 (1970).

\section{Organic Microanalysis of Submicrogram Samples}

\section{Douglas B. Hooker and Jack DeZwaan \\ The Upjohn Company \\ Kalamazoo, MI 49001}

\section{Introduction}

Information on the elemental composition of materials can be of great value in a variety of research problems. Obtaining this information is a problem in cases where only a very small amount (micrograms) of material is available since conventional microanalytical techniques require much larger (milligram) samples for each elemental determination. In these situations, a method which would determine all the elements present using a single, submicrogram sample would be useful. 